\title{
Chiropractic clinic offered referral kickbacks
}

Previously published at www.cmaj.ca

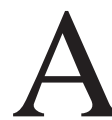

chiropractic clinic with locations in Ontario, Nova Scotia and

Manitoba offered lucrative kickbacks to physicians for referring clients to its five outlets until the College of Physicians and Surgeons of Ontario (CPSO) apparently stepped in to scuttle the payments as a result of CMAJ inquiries.

The offer of kickbacks in the form of financial compensation, arising out of referrals from doctors, came to light as a result of a CMAJ request for a "doctor's information kit" in accordance with instructions from an advertisement placed in the journal by the Low Back Clinic.

The kit included a document detailing appropriate patient referral criteria, which was followed by the proclamation: "In compliance with the C.P.S.O. standards, a $\$ 300$ documentations fee will be provided once the patient completes care."

A subsequent inquiry regarding the documentation required to receive a kickback drew an email response from Jackie Cornelius, manager of Low Back Clinic, which stated that the clinic "will give a documentation fee for your consultation notes, MRI reports and any other documentation you provide along with the referral once the patient has completed care."

But the clinic now reports that it has ceased offering the documentation fee as a result of a telephone call from the CPSO. Dr. Richard Liem, founder of the Low Back Clinic, says that offering the documentation fee was not his idea.

Liem says he did not realize the fee wasn't allowed until he spoke with the college. "We just found out that you're not allowed to do that whereas [someone else] asked if that was possible by your association and they said it was, according to him," Liem says.

Liem adds that the Low Back Clinic never actually provided any doctor with the documentation fee and that he himself thought the practice was dubious from the start. "It was something that I

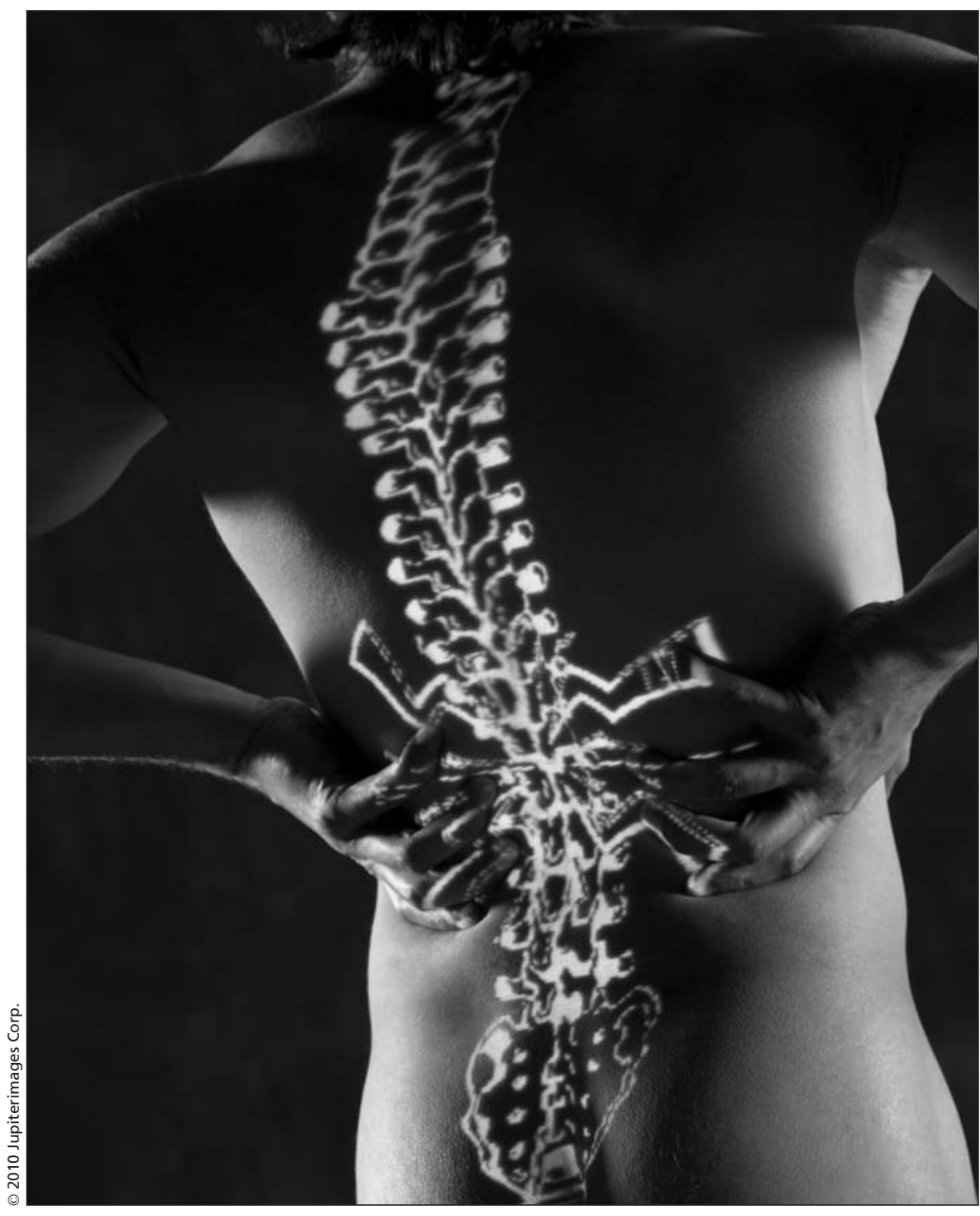

Treatment for discogenic back pain is at the core of a controversy over financial compensation offered to doctors for referring patients to a chiropractic clinic.

should have looked into myself because I had my doubts, but [someone else] assured me that it was possible."

The kickbacks are but the latest controversy surrounding the clinic. A treatment it offered for discogenic back pain was the subject of lawsuits and legal settlements in the United States (www.cmaj .ca/cgi/doi/10.1503/cmaj.109-3249).

Katherine Clarke, senior communications coordinator in the department of Policy and Communications of the
CPSO assures CMAJ that no such standards or documentations fees have ever been approved by the college. "

Clarke points out that Ontario Regulation 114/94, under the Medicine Act, stipulates that it is a conflict of interest for a physician to receive any benefit, directly or indirectly, from a supplier to whom the physician refers his or her patients. Yoni Freedhoff MD, Ottawa, Ont.

DOI:10.1503/cmaj.109-3277 